\title{
$\mathrm{X}$-ray 컨테이너 화물검색시스템의 전자선형가속기 주변 콘크리트 차페벽 내 방사화생성물에 대한 몬테카를로법 평가
}

조영호 ${ }^{*}$

${ }^{1}$ 대구가톨릭대학교 방사선학과

\section{Monte carlo estimation of activation products induced in concrete shielding around electron linac used in an X-ray container inspection system}

\author{
Young Ho Cho ${ }^{1 *}$ \\ ${ }^{1}$ Department of Radiological Science, Catholic University of Daegu
}

\begin{abstract}
요 약 고에너지 X-ray를 투시 방사선원으로 사용한 컨테이너 화물검색시스템에서 생성되는 광중성자에 의해 주변 콘크리트 차폐벽에서 발생되는 방사화생성물을 평가하였다. 몬테카를로 전산해석 코드인 MCNPX2.5.0을 사용하였으 며, 참조시스템은 국내 주요 항만에 설치된 $9 \mathrm{MeV}$ X-ray 고정식 양방향 컨테이너 화물검색시스템이다. $9 \mathrm{MeV}$ X-ray 조사에 따라 생성되는 광중성자의 (n,y) 반응에 의한 방사화생성물 재고량을 계산하고 이에 따라 야기되는 방사선 피폭선량을 계산하였다.
\end{abstract}

\begin{abstract}
Activation products generated by photoneutrons in concrete shielding wall around electron linac were estimated for a high energy X-ray container cargo inspection system. Monte carlo code, MCNPX2.5.0 was used for reference system of $9 \mathrm{MeV}$ fixed type dual-direction container cargo inspection system installed at major harbors in Korea. Activation products inventory generated by photoneutron $(\mathrm{n}, \mathrm{\gamma})$ reaction are estimated, and then radiation dose rate is calculated from the results.
\end{abstract}

Key Words : Container Inspection System, Monte Carlo Method, Activation Product, Photoneutron, Electron linac

\section{1. 서론}

X-ray를 이용한 화물검색시스템은 미국에서 "9.11 테 러”가 발생한 이후 국가안보 유지를 위해 국제적으로 그 이용이 더욱 가속화되고 증가되는 추세에 있다. 미국은 "9.11 테러”이후, “컨테이너안보구상(CSI, Container Security Initiative)"을 통해 미국으로 수출되는 컨테이너 화물에 대해서는 수출지에서 획득한 화물검색영상을 제 출할 것을 의무화하고 있다. 우리나라는 부산항이 미국과 이미 “메가항구(Mega-Ports)" 협력협정을 체결하였으며, 2003년 8월 부산항에 “컨테이너안보구상(CSI)"이행을 위
한 한-미 세관합동사무소가 개설되었다. 이러한 배경에서 X-ray를 이용한 화물검색시스템은 우리나라에서도 앞으 로 그 이용이 필연적으로 계속 증가할 수밖에 없으며 이 에 대한 연구와 분석 역시 향후 더욱 중요하다고 할 수 있다.

이러한 현실에 반하여 화물검색시스템과 관련한 산업 은 비교적 최근에 성장한 분야로서, 고에너지 X-ray 조사 로 발생하는 작업자 방사선 영향에 대한 분석은 다소 미 흡한 실정이다. 특히 광중성자에 의해 발생할 수 있는 방 사화생성물과 그로 인한 지발방사선의 영향에 대한 정량 적 분석은 현재 국제적으로도 이루어져 있지 않다. 이에

이 논문은 2010년도 대구가톨릭대학교 교내연구비 지원에 의한 것임.

*교신저자 : 조영호(cyhpp@hanmail.net)

접수일 10 년 01 월 12 일 수정일 10 년 03 월 02 일 게재확정일 10 년 03 월 18 일 
따라 본 논문에서는 현재 우리나라에 설치되어 있는 $9 \mathrm{MeV}$ X-ray 화물검색시스템에서 야기되는 광중성자에 의한 방사화영향에 대한 정량적 평가를 수행하였다.

\section{2. 방사화생성물 평가 이론}

수 $\mathrm{MeV}$ 이하의 광자(X-ray)와 물질과의 주요 상호작 용에는 광전효과, Compton효과, 쌍생성, 광핵반응이 있 다. 광핵반응(photonuclear reaction)이 발생할 확률은 광 전효과, Compton효과, 쌍생성이 발생할 확률을 모두 합 친 값보다는 10 의 수 제곱 배 작다. 광핵반응의 유형에는 $(\mathrm{\gamma}, \mathrm{p}),(\mathrm{\gamma}, \mathrm{n}),(\mathrm{\gamma}, \alpha),(\mathrm{\gamma}, 2 \mathrm{n}),(\mathrm{\gamma}, \mathrm{np})$ 등이 있다 [1].

이 중, 광중성자 반응, 즉 $(\mathrm{y}, \mathrm{n})$ 반응이 발생하기 위해 서는 X-ray의 에너지가 일정한 문턱에너지 값을 초과하 여야 하며, 이 문턱에너지 값은 핵종별로 구별되는 고유 의 물리적 특성이다. 화물검색시스템을 구성하는 가속기, 콘크리트 차폐벽, 콜리메이터 등의 주요 구성 원소들은 대부분 이러한 문턱에너지 값이 $9 \mathrm{MeV}$ 이하이며, 그 결 과 광중성자가 시설 내부에서 생성되게 된다. 특히 대부 분의 광중성자는 광자의 에너지가 높은 지점인 가속기와 콜리메이터에서 생성되므로, 가속기 주변의 콘크리트 차 폐벽은 X-ray에서 발생된 광중성자가 일차적으로 반응하 는 구조물로서 매우 중요하다.

일반적으로 중성자는 원자핵과 충돌할 때 탄성 또는 비탄성 산란을 한다. 산란을 통해 에너지를 잃은 중성자 는 핵에 포획 또는 흡수될 수 있으며, 이는 주로 $(n, \gamma)$ 반 응을 통해 이루어진다. 이러한 반응의 결과로 생성된 방 사성핵종들은 고유의 방사성붕괴를 통해 $\beta, \mathrm{\gamma}$ 등을 포한 한 2차(delayed) 방사선을 방출하며 안정 원소로 바뀌게 된다 $[2,3]$.

중성자 포획 반응에 의해 발생하는 방사성핵종의 생성 은 다음 식으로 기술된다 $[4,5]$.

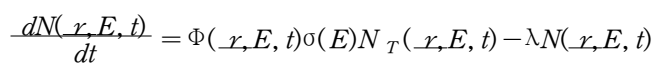

여기서, $N(r, E, t)=$ 중성자 조사로 발생하는 방사성 핵종의 수 [nuclide $\left./ \mathrm{cm}^{3}\right]$

$$
\begin{aligned}
& \left.\Phi(r, E, t)=\text { 중성자속 [neutrons } / \mathrm{cm}^{2} \cdot \mathrm{sec}\right] \\
& \sigma(E)=(n, \mathrm{\gamma}) \text { 반응단면적 }\left[\mathrm{cm}^{2}\right] \\
& N_{T}(r, E, t)=\text { 중성자 조사를 받는 타겟 핵종 } \\
& \left.\quad \text { 의 수 [nuclide } / \mathrm{cm}^{3}\right] \\
& \lambda=\text { 붕괴상수 }[\mathrm{sec}-1]
\end{aligned}
$$

위 식을 풀어서 초기조건 등을 대입하면 다음과 같은 결과를 얻는다.

$$
N_{a c t}(t)=\frac{\int_{E} \int_{V} \Phi \sigma N_{T} d V d E}{\lambda}\left(1-e^{-\lambda t}\right)
$$

여기서, $N_{a c t}(t)$ = 중성자 조사로 발생하는 방사성핵종 의 수 [nuclide]

\section{3. 화물검색시스템}

화물검색시스템은 가속기, 검출기, 이송대차, 방사선 안전 및 방호장비, 기타 하드웨어, 소프트웨어 등 컨테이 너를 검색하는데 필요한 모든 장비 및 관련 장치와 구조 물, 건물 등이 포함된다 [6]. 가속기는 최고 $400 \mathrm{~mm}$ 두께 철판을 투과할 수 있는 $9 \mathrm{MeV}$ X-ray 빔을 발생, 방출하는 $9 \mathrm{MeV}$ 전자선형가속기로서 수평 및 수직 양방향으로 모 두 2 대가 배치된다. 가속기로부터 방출되는 X-ray 빔의 조사각도는 수평방향 $22.75^{\circ}$, 수직방향 $16.5^{\circ}$ 로 설계되어 길이 $20 \mathrm{~m}$, 폭 $2.5 \mathrm{~m}$, 최대 높이 $4.6 \mathrm{~m}$ 크기의 컨테이너와 트레일러 차량 전체를 투과하며, 투시대상 컨테이너의 내 부위치별 투과력과 분해능의 차이를 최소할 수 있도록 설계되어 있다. 그림 1 은 수직 및 수평 양방향 화물검색 시스템의 단면도이다.

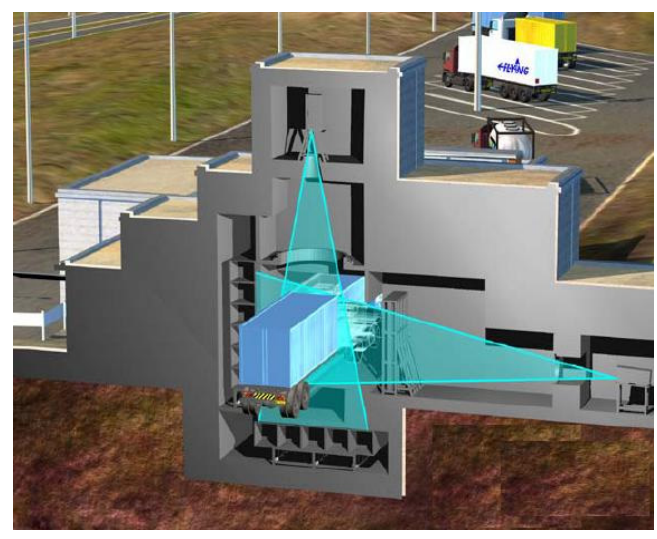

[그림 1] 양방향 화물검색시스템 단면도

컨테이너를 투과한 X-ray는 검출기에서 수집된다. 검 출기는 데이터 획득 및 제어장치 등과 연결되어 있으며, 검출기에서 수집된 투과 X-ray는 영상처리 소프트웨어를 통해 처리되어 컨테이너 검색영상으로 재구성된다. 그림 2는 양방향 컨테이너 화물검색시스템의 전체적인 구조에 
대한 그림이며, 그림 3은 가속기와 검출기의 배치 형태에 대한 그림이다.

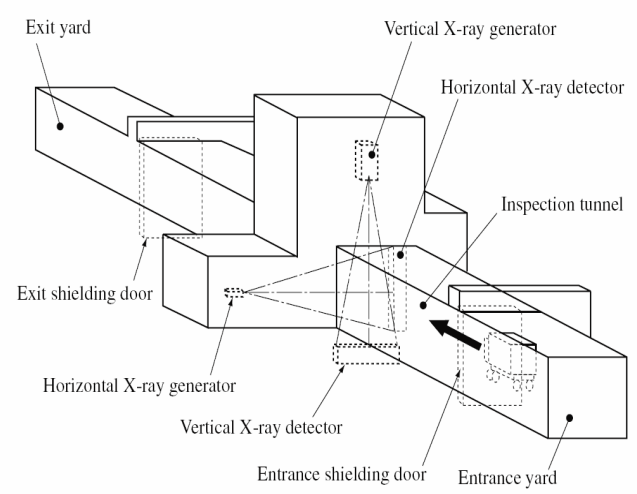

[그림 2] 양방향 화물검색시스템의 구조

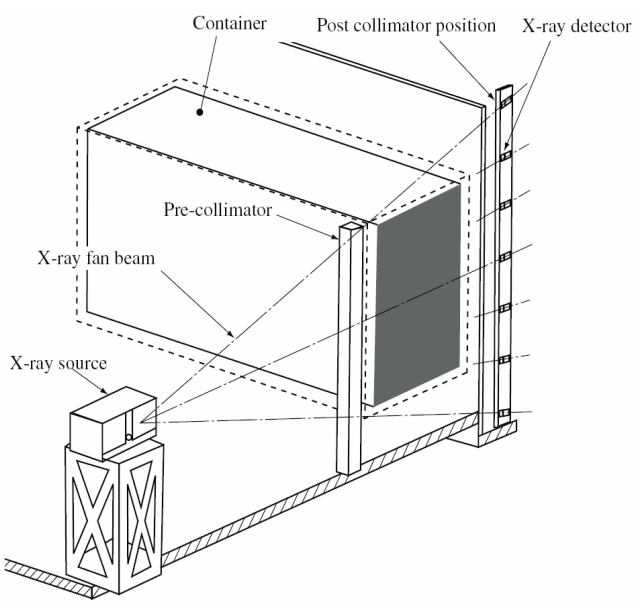

[그림 3] 가속기 및 검출기 배치형태

\section{4. 몬테카를로 시뮬레이션}

MCNPX(Monte Carlo N-Particle eXtended) 전산해석 코드는 미국 Los Alamos 연구소에서 몬테카를로 시뮬레 이션 기법을 이용하여 개발한 3 차원 방사선 수송 해석 전 산코드로서, 3 개(전자, 광자, 중성자)의 입자만을 모사할 수 있는 MCNP(Monte Carlo N-Particle) 전산해석 코드를 최대 34 개의 입자들(양성자, 양전자, 알파입자 등 추가)을 고에너지 영역까지 모사할 수 있도록 적용범위를 확대하 여 개발된 전산해석 코드이다 $[7,8]$.

MCNPX2.5.0 전산해석 코드 계산은 서울대학교 중앙 전산원에 구축되어 있는 Power PC970 $2.2 \mathrm{GHz}$ 2-way Supercomputer 하드웨어, SuSe Linux Enterprise Server 9 for ppc64/kernel 2.6.5-7.139 소프트웨어, GNU 컴파일러 (gcc, g77, g++) IBM XLC 7.0, XLF 9.1 컴파일러 환경에 서 수행하였다.

MCNPX2.5.0 코드를 이용하여 몬테카를로 시뮬레이 션을 수행하기 위한 화물검색시스템에 대한 모델링은 그 림4 및 그림5와 같다.

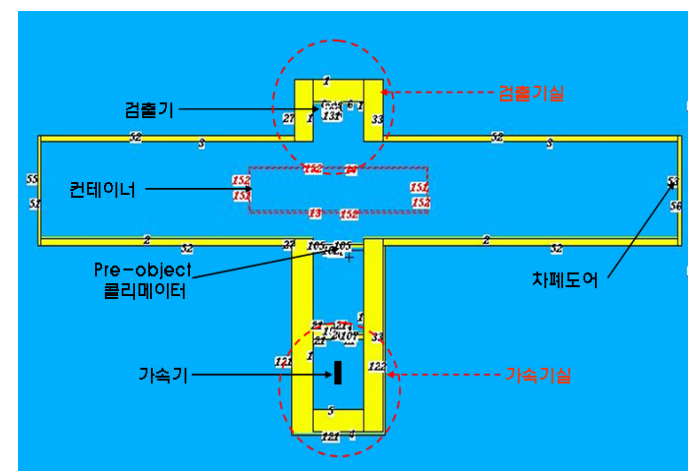

[그림 4] 평면도

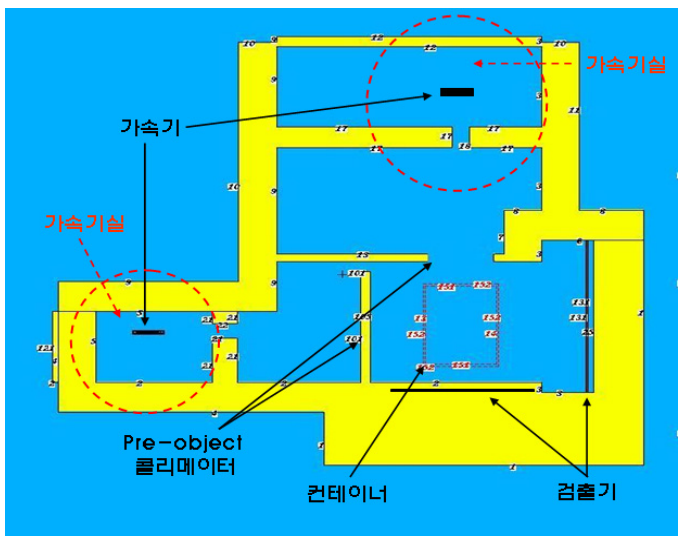

[그림 5] 단면도

\section{5. 결과 및 분석}

\section{1 방사화생성물}

본 논문에서는 X-ray 빔이 통과하는 경로인 가속기와 콜리메이터 및 차폐벽에서 주로 생성되는 광중성자가 가 속기 주변 차폐벽과 반응할 때 발생되는 방사화생성물을 계산하였다. 콘크리트 표면 및 내부에서 발생되는 방사화 생성물 종류와 방사능 양은 표 1과 같다 $[9,10]$. 이들은 고유의 붕괴 과정을 통해 여러 종류의 붕괴 방사선들을 방출하며, 이러한 붕괴 방사선들은 작업종사자에게 불필 요한 방사선 피폭을 야기할 수 있다. 
[표 1] 화물검색시설 내 방사화생성물

\begin{tabular}{|c|c|c|c|c|}
\hline \multirow{2}{*}{$\begin{array}{c}\text { 방사화 } \\
\text { 생성물 }\end{array}$} & \multirow{2}{*}{ 반감기 } & \multicolumn{3}{|c|}{ 방사능 $(\mathrm{Ci})$} \\
\cline { 3 - 5 } & & 1년 운전 후 & 3 년 운전 후 & 상대오차 \\
\hline${ }^{3} \mathrm{H}$ & $12.346 \mathrm{Y}$ & $2.85 \mathrm{E}-12$ & $7.52 \mathrm{E}-12$ & 0.05 \\
\hline${ }^{19} \mathrm{O}$ & $27.1 \mathrm{~S}$ & $2.03 \mathrm{E}-08$ & $2.03 \mathrm{E}-08$ & 0.04 \\
\hline${ }^{24} \mathrm{Na}$ & $15.02 \mathrm{H}$ & $6.18 \mathrm{E}-04$ & $6.18 \mathrm{E}-04$ & 0.04 \\
\hline${ }^{24} \mathrm{mNa}$ & $0.02 \mathrm{~S}$ & $1.44 \mathrm{E}-03$ & $1.44 \mathrm{E}-03$ & 0.05 \\
\hline${ }^{27} \mathrm{Mg}$ & $9.46 \mathrm{M}$ & $7.54 \mathrm{E}-04$ & $7.54 \mathrm{E}-04$ & 0.05 \\
\hline${ }^{28} \mathrm{Al}$ & $2.24 \mathrm{M}$ & $4.29 \mathrm{E}-03$ & $4.29 \mathrm{E}-03$ & 0.05 \\
\hline${ }^{31} \mathrm{Si}$ & $157.3 \mathrm{M}$ & $9.16 \mathrm{E}-04$ & $9.16 \mathrm{E}-04$ & 0.05 \\
\hline${ }^{41} \mathrm{Ca}$ & $1.03 \mathrm{E} 5 \mathrm{Y}$ & $1.58 \mathrm{E}-03$ & $4.50 \mathrm{E}-03$ & 0.05 \\
\hline${ }^{45} \mathrm{Ca}$ & $163.8 \mathrm{D}$ & $6.78 \mathrm{E}-05$ & $9.28 \mathrm{E}-05$ & 0.04 \\
\hline${ }^{47} \mathrm{Ca}$ & $4.535 \mathrm{D}$ & $1.86 \mathrm{E}-06$ & $1.86 \mathrm{E}-06$ & 0.05 \\
\hline${ }^{49} \mathrm{Ca}$ & $8.72 \mathrm{M}$ & $9.28 \mathrm{E}-06$ & $9.28 \mathrm{E}-06$ & 0.04 \\
\hline${ }^{55} \mathrm{Fe}$ & $2.73 \mathrm{Y}$ & $4.98 \mathrm{E}-04$ & $9.64 \mathrm{E}-04$ & 0.05 \\
\hline${ }^{59} \mathrm{Fe}$ & $44.5 \mathrm{D}$ & $4.25 \mathrm{E}-05$ & $4.82 \mathrm{E}-05$ & 0.05 \\
\hline
\end{tabular}

표 1에 제시된 수치는 가속기 주변 차폐벽 내에 존재 하는 핵종별 방사능 수치이다. 표 1 의 가장 마지막 열에 는 이 방사능 수치에 대한 통계적 오차가 제시되어 있는 데, 이는 MCNPX 시뮬레이션의 결과물에서 기본적으로 제공되는 “상대오차" 값으로서 일반적으로 이 값이 0.1 이하가 되어야 계산 결과를 신뢰할 수 있다. 이러한 방사 화생성물 재고량 평가 결과는 그 자체로도 의미를 가지 나, 본 논문의 주요 목적 중 하나로서 이후 수행되는 방 사화생성물에 의한 방사선량률 계산에 이용된다.

표 1 에 제시된 방사화생성물의 반감기에 따라서 포화 상태에 도달하는 시간은 서로 다르나, 보수적인 방사선량 률 계산을 위해서는 충분히 포화 상태에 이른 결과가 요 구된다. ${ }^{3} \mathrm{H},{ }^{41} \mathrm{Ca},{ }^{45} \mathrm{Ca},{ }^{55} \mathrm{Fe},{ }^{59} \mathrm{Fe}$ 등 5 개 핵종을 제외한 대부분의 방사성핵종들은 검색시설 운전 후 1 년이 경과 하면 그 방사능이 포화상태에 이른다. 이 들 5 개 핵종들 중 ${ }^{45} \mathrm{Ca},{ }^{59} \mathrm{Fe}$ 등 2 개 핵종은 운전 후 3 년이 경과하면 방사 능이 포화상태에 이르며, 나머지 3개 핵종은 반감기가 매 우 긴 핵종들로서 포화상태에 도달하기에 시간이 많이 요구되나 방사선 피폭에 기여하는 바가 없거나 또는 매 우 적기 때문에 포화 도달 여부가 중요하지는 않다.

따라서 본 논문에서는 이후 진행될 방사선량률 계산을 위해서는 3 년 운전 후 누적된 방사능을 기초로 평가 및 분석을 수행하였다.

\section{2 방사선량률}

국제 방사선 방호 위원회(ICRP, International Commission on Radiological Protection)는 작업종사자에 대한 선량제
한치를 $20 \mathrm{mSv} / \mathrm{yr}$ 로 정하고 있으며, 이를 연간 작업시간 2,000 을 가정하여 환산하면 $10 \mu \mathrm{Sv} / \mathrm{hr}$ 의 방사선량률 제 한치를 구할 수 있다 [11]. 본 연구에서 계산된 방사화생 성물 재고량을 기초로 가속기실 중앙에서 평가된 작업종 사자 방사선량률은 $0.97 \mu \mathrm{Sv} / \mathrm{hr}$ 로서, ICRP의 제한치는 넘지 않는다는 것을 확인할 수 있다. 그러나 이는 결코 낮은 수치의 방사선량률은 아니며 작업종사자 피폭선량 을 ALARA (As Low As Reasonably Achievable)로 유지 하기 위해서는 피폭 저감 방안이 강구될 필요가 있다.

\section{6. 결론}

1. 운전 정지 직후 가속기실 내에서의 방사선량률은 주로 ${ }^{24} \mathrm{Na},{ }^{27} \mathrm{Mg},{ }^{28} \mathrm{Al}$ 등의 방사성핵종에 기인하며, 불필요한 작업종사자 피폭을 방지하기 위해 운전 정지 직후에는 가속기실 출입 및 작업을 금지하는 것이 바람직하다. ${ }^{24} \mathrm{Na},{ }^{27} \mathrm{Mg},{ }^{28} \mathrm{Al}$ 핵종에 의한 방 사선량률은 각각 $0.18 \mu \mathrm{Sv} / \mathrm{hr}, 0.09 \mathrm{~Sv} / \mathrm{hr}, 0.54 \mu$ $\mathrm{Sv} / \mathrm{hr}$ 이다.

2. 중대사고 등이 발생하여 불가피하게 가속기실에 출 입해야 할 경우에는 적절한 차폐가 필요하며 최대 한 짧은 시간 동안에 작업을 종료할 필요가 있다.

3. 운전 정지 1 시간 정도가 경과하면 가속기실 내에 서의 방사선량률은 크게 감소하는데 이는 주로 ${ }^{27} \mathrm{Mg},{ }^{28} \mathrm{Al}$ 과 같이 반감기가 짧은 방사성핵종들이 붕괴하여 그 양이 크게 감소한 것에 기인한다. 그러 나 ${ }^{24} \mathrm{Na}$ 방사성핵종들에 의한 방사선량률은 여전히 높은 수준을 유지하고 있으므로 이에 대한 대비책 이 요구된다.

\section{참고문헌}

[1] F. Jallu, A. Lyoussi, E. Payan, H. Recroix, A. Mariani, G. Nurdin, A. Buisson and J. Allano, "Photoneutron Production in Tungsten, Praseodium, Copper and Beryllium by Using High Energy Electron Linear Accelerator", Nuclear Instruments and Methods in Physics Research B 155, pp. 373-381, 1999.

[2] D. J. Hughes, "Pile Neutron Research", Addison -Wesley Publishing Company, Inc., 1953.

[3] Richard E. Faw and J. Kenneth Shultis, "Radiological Assessment: Sources and Doses", American Nuclear 
Society, Inc., 1999.

[4] Harold Elford Johns and John Robert Cunningham, "The Physics of Radiology", Charles C Thomas Publisher, 1983.

[5] James E. Turner, "Atoms, Radiation, and Radiation Protection”, John Wiley \& Sons, Inc., 1995.

[6] Posdata Co. Ltd., "Technical Specifications of Container Inspection System”, 2005.

[7] Pelowitz, D. B., "MCNPXTM user's manual version 2.5.0", LA-CP-05-0369, 2005.

[8] Hendricks, J. S., "MCNPX extensions version 2.5.0", LAUR-05-2672, 2005.

[9] IAEA, "Handbook on Nuclear Activation Data", Technical Report Series No.273, STI/DOC/10/273, 1987.

[10] ICRP, "Radionuclide Transformations: Energy and Intensity of Emissions", ICRP Publication 38, Pergamon Press, 1983.

[11] ICRP, "1990 Recommendations of the International Commission on Radiological Protection", ICRP Publication 60, Pergamon Press, 1990.

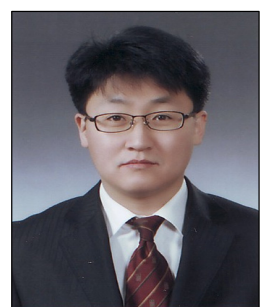

- 1997년 2월 : 서울대학교 공과대 학원 원자핵공학과 (원자력석사)

- 2006년 8월 : 서울대학교 공과대 학원 원자핵공학과 (원자력박사)

- 2004년 7월 2006년 4월 : 포 스데이타(주) 선임연구원

- 2006년 4월 2008년 8월 : 전 략물자관리원 조사연구팀장

- 2008년 9월 현재 : 대구가톨릭대학교 방사선학과 교 수

<관심분야>

방사선안전 및 방호, 원자력정책 